\title{
O papel do futebol no combate às desigualdades e na afirmação do papel da mulher: uma análise das estratégias de comunicação dos clubes de Portugal e Brasil no Dia Internacional da Mulher
}

\author{
Fernando Jesus da Rocha \\ Universidade da Beira Interior - fernando.rocha@ubi.pt \\ Ricardo Morais \\ Universidade da Beira Interior - ricardo.morais@labcom.ubi.pt
}

\section{Resumo}

Neste artigo procuramosverificaraimportância que os clubes de futebol atribuem ao combate das desigualdades e em particular à afirmação do papel da mulher. Consideramos, para esse efeito, os 17 Objetivos do Desenvolvimento Sustentável, mas focamo-nos em particular no quinto, que versa sobre a igualdade de género e o empoderamento feminino. Através de um estudo de caso múltiplo, procedemos a uma análise comparativa das publicações realizadas pelos clubes de Portugal e Brasil, na rede social Facebook, para assinalar o Dia Internacional da Mulher. Os resultados evidenciam que os clubes estão atentos à data e procuram, através das diferentes publicações, alertar para o papel da mulher, numa estratégia de comunicação orientada para a responsabilidade social.

Palavras-chave: mulher, futebol, comunicação, responsabilidade social.

\section{The role of football in combating inequalities and affirming the role of women: an analysis of the communication strategies of the clubs of Portugal and Brazil on International Women's Day}

\begin{abstract}
In this article, we seek to verify the importance that football clubs attach to combating inequalities and, in particular, to affirm the role of women. For this purpose, we consider the 17 Sustainable Development Goals, but we focus in particular on the fifth, which deals with gender equality and women's empowerment. Through a multiple case study, we carried out

a comparative analysis of publications made by clubs in Portugal and Brazil on the social network Facebook to mark International Women's Day. The results show that the clubs are aware of the date and seek, through different publications, to raise awareness of the role of women in a communication strategy geared towards social responsibility.
\end{abstract}

Keywords: woman, soccer, communication, social responsibility. 


\section{INTRODUÇÃO}

O futebol deixou de ser um mero desporto para se tornar um elemento social, cultural e mercadológico (Wisnik, 2008), assumindo uma inequívoca capacidade de sensibilização e mobilização social. Ao transcender os aspectos do jogo, posicionou-se de modo determinante como um agente de transformação da sociedade, o que, de algum modo, contrasta com os poucos esforços académicos que entendem o desporto enquanto campo social. O sociólogo Richard Giulianotti, um dos principais investigadores do mundo sobre as dimensões históricas e socioculturais do futebol, afirma que "embora seja o principal desporto de equipa do mundo, foi somente na década de 1960 que a importância social do futebol recebeu substantiva e separada atenção de cientistas sociais e historiadores" (Guilianotti, 1994, p. 9).

De acordo com autores como Walters e Tacon (2011), a dimensão popular do desporto permite atingir uma ampla gama de camadas sociais, faixas etárias e populações distantes geograficamente, transformando-o num vetor importante de influência no modo de vida e no quotidiano. Essa reflexão justifica a premência em abordar este tema e discutir o futebol como um instrumento de impacto e consciencialização social, capaz de intervir no comportamento dos cidadãos. É também neste sentido e por se acreditar que a adoção de medidas de responsabilidade social pode melhorar substancialmente a imagem de um clube, que este comportamento se tornou uma tendência nos últimos anos (Kolyperas, 2012).

Apesar de essa valorização da imagem surgir muitas vezes com propósitos económicos, neste estudo não é a dimensão financeira que se quer investigar, ou melhor, é para lá dessa questão que se pretende analisar, uma vez que os clubes podem fazer ações tendo em vista o lucro. No entanto, o que interessa perceber é se os clubes pensam para além da perspectiva mercadológica. Frans Timmermans, Primeiro Vice-Presidente da Comissão Europeia, realça o interesse que as grandes corporações começam a demonstrar em relação aos aspectos sociais e sustentáveis, destacando que este posicionamento não é apenas um "caso de negócio", mas "uma sensação crescente de que, como pais, como cidadãos, eles também desejam contribuir para um mundo melhor, simplesmente, porque é a coisa certa a fazer" (Frost \& Sullivan, 2017, p. 5).

Por outro lado, o desporto, como uma instituição que deveria ser inclusiva, carece de avanços notáveis. Anderson (2009) realça que o desporto, sobretudo na esfera da competição, constitui ainda um campo de afirmação masculinidade, em linha com 
a ideia também, defendida por Pierre Bourdieu (2001) que alerta para a recorrente expressão da dominação masculina. "Como um regime de género altamente segregado, homofóbico, sexista e misógino, o desporto não apenas contribui para a ordem de género, mas também reproduz uma forma conservadora de masculinidade que tem custos consideráveis para ambos os sexos" (Anderson, 2009, p. 4).

O futebol constitui, neste contexto, um caso paradigmático de exibição de comportamentos históricos de dominação masculina, mas sobretudo de segregação e afastamento das mulheres. Mas o futebol pode também ser, como salienta Constantino (2006, p. 9), um meio de expressão da resistência em relação ao controlo e à dominação, uma vez que este tem a possibilidade de dar visibilidade e legitimar mensagens de caráter ideológico e social.

É neste sentido que se torna relevante desenvolver uma análise sobre o posicionamento e as estratégias de comunicação dos clubes de futebol, porque só dessa forma será possível perceber se existe uma real preocupação por parte dos clubes em relação ao papel da mulher na sociedade.

A comunicação, de um modo abrangente, e em particular a comunicação em rede (Castells, 2003), configura-se neste contexto como um campo com potencial quase ilimitado, uma vez que devido ao seu alcance, pode fazer com que as mais variadas mensagens alcancem todo o tipo de públicos. Se considerarmos em particular a emergência da Internet, concluímos que ela permitiu uma conexão direta com milhões de pessoas, o que também se verificou na esfera futebolística. A questão que se coloca é então a de saber se os clubes fazem uso da popularidade, penetração social e capacidade informativa que conquistaram, para transmitir mensagens de Responsabilidade Social (Walters \& Tacon, 2011).

Assim, olhando para lá da dimensão desportiva, nesta investigação exploramos a possibilidade de o desporto e, em particular, o futebol, ser visto como um instrumento de consciencialização e transformação social através da sua capacidade de influência, focando, essencialmente, na importância crescente de pensar em estratégias que ajudem a combater as desigualdades da sociedade e, no caso particular deste trabalho, a afirmar o papel da mulher. 


\section{A SOCIEDADE MODERNA E OS OBJETIVOS GLOBAIS PARA O DESENVOLVIMENTO SUSTENTÁVEL}

Leave no one behind, a premissa da Agenda 2030 da ONU, divulgada no momento de lançamento dos 17 Objetivos para o Desenvolvimento Sustentável no mundo (Santos, Antunes \& Guedes, 2019), transmite uma mensagem que encontra um sentido de complementaridade no prólogo do livro "A Arte da Vida" (Bauman, 2009), onde o autor cita o filósofo Epicteto para aludir à valorização do indivíduo e à sua idiossincrasia, realçando a importância de fomentar o pensamento coletivo: "Você não é uma entidade isolada, mas uma parte única e insubstituível do cosmo".

Partindo dessa premissa, identificamos no desporto, enquanto reflexo de questões sociais (L'Etang, 2006) - como a discriminação racial, a desigualdade social e, sobretudo, as diferenças de género - , a possibilidade de assumir um papel de protagonismo no sentido de dar visibilidade a essas temáticas e contribuir para o desenvolvimento sustentável e a evolução da sociedade como um todo. L'Etang apresenta esta proposta na medida em que considera o desporto como "um microcosmo da vida social, que revela valores subjacentes e relações poderosas. Práticas sociais são refletidas no desporto e o desporto é uma arena onde a variedade de convenções, costumes, e questões éticas e problemáticas são levantadas" (2006, p. 12).

Se é verdade que a sociedade moderna é hoje entendida como um espaço de transformações, naquilo que Bauman (2001) chama de sociedade líquida, sabemos também que muitas dessas transformações têm sido responsáveis pela criação de desigualdades a diferentes níveis.

Foi nesse contexto, de crescimento das desigualdades, que as Nações Unidas decidiram desenvolver um conjunto de ações que ajudassem a tornar o mundo mais justo e equilibrado. Em 2000, após a realização da Cúpula do Milénio, foi aprovada a Declaração (Mibielli \& Barcellos, 2014, p. 224) que impulsionou o estabelecimento de metas globais para a redução da pobreza e os Objetivos do Desenvolvimento Mundial, firmados em 2001 (Hulme, 2007, p. 12).

Os Objetivos do Milénio sinalizaram uma preocupação global jamais vista. "Nunca um conjunto de objetivos mundiais a serem alcançados por todos os países e em todos os níveis foram sistematizados num único documento, com metas e indicadores claros para monitorá-los" (Okado \& Quinelli, 2016, p. 118). Porém, em 2015 os objetivos foram redefinidos com a finalidade de abranger mais elementos. Deste modo, foram elencados 17 Objetivos do Desenvolvimento Sustentável (ODS) na 
Agenda 2030. Embora a meta seja 2030, há na Europa - e no mundo - a necessidade premente de cumprir os objetivos o mais depressa possível. Empresas, governos e sociedade civil precisam desenvolver ações com urgência, a fim de reconquistar a confiança dos cidadãos e cuidar das dimensões sociais do crescimento (Okado \& Quinelli, 2016, p. 33).

Os 17 Objetivos do Desenvolvimento Social passaram então a focar os seguintes aspetos: Erradicar a pobreza; Erradicar a fome; Saúde de qualidade; Educação de qualidade; Igualdade de género; Água potável e saneamento; Energias Renováveis e acessíveis; Trabalho digno e crescimento económico; Indústria, inovação e infraestruturas; Reduzir as desigualdades; Cidades e comunidades sustentáveis; Produção e consumo sustentáveis; Ação climática; Proteger a vida marinha; Proteger a vida terrestre; Paz, justiça e instituições eficazes.

Identificamos nos ODS o fomento para a mudança necessária e a garantia de um futuro mais justo e igualitário, e é nesse contexto que consideramos que o futebol pode ser evocado como um catalisador de visibilidade social, na medida em que conquistou importância social e cultural, grande capacidade de mobilização da sociedade e das suas instituições (Cardoso et al., 2007, p. 123), o que lhe confere também acrescidas responsabilidades.

\section{ALCANÇAR A IGUALDADE DE GÉNERO E EMPODERAR TODAS AS MULHERES E RAPARIGAS}

Entre os 17 objetivos para o desenvolvimento sustentável, destacamos neste trabalho o quinto objetivo, que tem por missão alcançar a igualdade de género e empoderar todas as mulheres e raparigas. Para além do objetivo mais geral, são apresentados um conjunto de objetivos específicos, a serem alcançados para a Agenda 2030, que se centram nas seguintes dimensões, apresentadas no site desenvolvido pelo BCSD Conselho Empresarial para o Desenvolvimento Sustentável:

Acabar com todas as formas de discriminação contra todas as mulheres e meninas;

Eliminar todas as formas de violência contra todas as mulheres e meninas nas esferas públicas e privadas, incluindo o tráfico e exploração sexual e de outros tipos; 
Eliminar todas as práticas nocivas, como os casamentos prematuros, forçados e envolvendo crianças, bem como as mutilações genitais femininas;

Reconhecer e valorizar o trabalho de assistência e doméstico não remunerado; Garantir a participação plena e efetiva das mulheres e a igualdade de oportunidades para a liderança em todos os níveis de tomada de decisão na vida política, económica e pública;

Assegurar o acesso universal à saúde sexual e reprodutiva e os direitos reprodutivos;

Realizar reformas para dar às mulheres direitos iguais aos recursos económicos; Aumentar o uso de tecnologias de base, em particular as tecnologias de informação e comunicação, para promover o empoderamento das mulheres;

Adotar e fortalecer políticas sólidas e legislação aplicável para a promoção da igualdade de género e o empoderamento de todas as mulheres e meninas, a todos os níveis".

As diferentes dimensões que integram este quinto objetivo convergem com os preceitos defendidos por autores como Eric Anderson (2009) e Pierre Bourdieu (2001) e são particularmente importantes no contexto deste trabalho, uma vez que vão orientar a recolha de dados, ou seja, tentaremos identificar se a comunicação efetuada pelos clubes procura promover a igualdade de género e o empoderamento das mulheres.

Interessa também destacar que as estruturas de dominação masculina são produto de um trabalho incessante de projeção e reprodução, que se legitimam a partir de agentes institucionalizados como família, igreja, escola, Estado (Bourdieu, 2001, p. 46) e, acrescentamos nós, o desporto, especialmente se pensarmos no futebol. Vale lembrar que os meninos são ainda educados para participarem de modalidades que evidenciam as suas valências físicas, numa evidente alusão ao poder do homem e à fraqueza da mulher (Anderson, 2009, p. 4).

Bourdieu (2001) destacou que o domínio dos homens é realizado por meio de um sistema entrelaçado de oposições cognitivas e padrões sociais nas famílias, escolas e cujo estado se baseia na reificação do homem dominante e da 
mulher submissa. Ele (como tantos teóricos de género) argumentou que o sistema entrelaçado de categorias cognitivas e diferenças sociais objetivas produz a (falsa) perceção de que existem diferenças profundas entre os sexos. Isso é algo claro e facilmente explicado no desporto, pois masculinidade é sinónimo de desporto (Anderson, 2009, p. 7)

É também no trabalho do sociólogo francês, e mais particularmente na obra "Questões de Sociologia" (1983), que o autor reflete acerca da tarefa social do desporto, destacando a importância de considerar "a legitimidade de uma ciência social como objeto científico separado, estabelecendo a partir de quando, ou melhor, a partir de que conjunto de condições sociais se pode verdadeiramente falar de desporto" (Bourdieu, 1983, p. 184). Desta forma o autor procura desassociar o que é considerado como sendo apenas o jogo, daquilo que é o desporto enquanto campo social, um espaço que pode ser dotado de discussões mais profundas, que transcendem a mera prática desportiva. É precisamente nesta linha que desenvolvemos o presente estudo, considerando o desporto, e em particular o futebol, como uma arena mais ampla de debate e intervenção na sociedade.

\section{A RESPONSABILIDADE SOCIAL NAS ORGANIZAÇÕES DESPORTIVAS}

Um dos primeiros autores a teorizar sobre a responsabilidade social definiu o conceito centrado na ação dos empresários e no seu compromisso de "perseguir políticas, de tomar decisões ou de seguir as linhas de ação desejáveis em termos dos objetivos e valores da nossa sociedade" (Bowen, 1953, p. 6). Quase 70 anos depois, verificamos que os preceitos de responsabilidade social ainda encontram resistência no mundo corporativo.

Há um esforço global para que as organizações se consciencializem quanto à importância de investir no ser humano e de resolver alguns dos seus problemas básicos. Essa foi uma das grandes preocupações da Carta dos Direitos Fundamentais, definidos pela União Europeia, no Livro Verde, em Bruxelas, que identifica na responsabilidade social "a integração voluntária de preocupações sociais e ambientais por parte das empresas nas suas operações” (2001, p. 7). Segundo Tichy, McGill e Clair (1997), já não basta à organização tentar corrigir os seus erros através de ações pontuais. É fundamental que a responsabilidade social e as boas ações façam parte do 
núcleo da empresa, dos objetivos de negócio, das estratégias e missão da organização. É hora de iniciar uma discussão séria sobre como as empresas de todas as formas e tamanhos podem desempenhar um papel importante na condução de uma sociedade mais sustentável e inclusiva, ao mesmo tempo que atendem aos seus objetivos corporativos de geração de valor e obtenção de vantagem competitiva (Frost \& Sullivan, 2017, p. 7).

No sentido de haver um equilíbrio que possa atender os objetivos mercadológicos, sociais e sustentáveis de uma organização, destacamos também neste trabalho a Teoria dos Stakeholders, que preconiza tomadas de decisão que satisfaçam os anseios de todos os públicos em torno da corporação. Freeman e McVea (2001) referem que o termo stakeholder passou a fazer parte do mundo corporativo em 1963, sendo utilizado para designar "todos os grupos sem os quais a empresa deixaria de existir" (p.2).

No caso do futebol, os stakeholders são os jogadores, a equipa técnica, o corpo diretivo, os conselheiros, associados e, principalmente, os adeptos (Pedersen, 2017). Recorremos a esta teoria uma vez que acreditamos que o clube tem de se preocupar, não apenas em devolver aos adeptos eventuais resultados desportivos, mas transcender a lógica das quatro linhas, interessando-se pelo bem-estar da parte mais numerosa e importante dos seus stakeholders.

Um estudo elucidativo sob o prisma de desenvolver um panorama de teorias relativamente ao campo da Responsabilidade Social Corporativa (RSC), foi escrito por Garriga e Melé (2004), que discorrem, especialmente, sobre quatro abordagens teóricas acerca da RSC, a partir de uma série de autores seminais.

Para alguns, transmite a ideia de responsabilidade legal ou obrigação; para outros, significa comportamento socialmente responsável no sentido ético; para outros ainda, o significado transmitido é o de "responsável por" em um modo causal; muitos simplesmente o equiparam a uma contribuição de caridade; alguns acham que significa consciência social; muitos dos que o abraçam com mais fervor veem-no como um mero sinónimo de legitimidade no contexto de pertencer ou ser adequado ou válido; alguns veem uma espécie de dever fiduciário impondo padrões mais elevados de comportamento aos empresários do que aos cidadãos em geral (Votaw, 1973, p. 25).

As quatro abordagens mencionadas têm como mote a aplicação da RSC no cerne da organização, a diferir, entretanto, do modo como é percebida esta estratégia para 
os objetivos organizacionais. A primeira teoria apresentada por Garriga e Melé (2004) é a Teoria Instrumental, que percebe a RSC somente como um instrumento de criação de riqueza, onde a sua prática, essencialmente, visa a consecução de resultados económicos, um paradoxo ao que se propõe neste estudo.

A segunda abordagem são as teorias políticas, que enfatizam o poder social da corporação na relação com a sociedade (Garriga \& Melé, 2004), ou seja, considera o poder que uma organização tem, propondo, necessariamente, uma cooperação social a partir de deveres e direitos sociais.

As teorias integrativas, a terceira mencionada, já avista a corporação com foco na satisfação das demandas sociais. Os autores que defendem essa abordagem "costumam argumentar que os negócios dependem da sociedade para a sua continuidade e crescimento, e até mesmo para a existência dos próprios negócios" (Garriga \& Melé, 2004, p. 53).

Por fim, encontramos as teorias éticas, que entendem que a relação entre sociedade e organizações deve estar inserida em valores éticos, o que, logicamente, leva as empresas a perceberem a RSC numa perspectiva onde "devem aceitar as responsabilidades sociais como uma obrigação ética acima de qualquer outra consideração" (Garriga \& Melé, 2004, p. 53), sejam elas económicas, como a primeira teoria, políticas, como a segunda ou filantrópicas, como a terceira.

O grande desafio é transpor as variadas perspectivas sobre Responsabilidade Social para o desporto. Pedersen (2017) menciona que uma série de autores aplicam, ao setor desportivo, o termo "Responsabilidade Social Desportiva" quando se associam os campos, um conceito em transformação constante, alvo de atenção das organizações desportivas desde o início dos anos 90 (Panton, 2012). As organizações desportivas, em função da cobertura mediática de que dispõem, podem transmitir uma imagem que seja capaz de reforçar as percepções positivas que se pode ter da marca (Babiak \& Trendafilova, 2011).

O que acontece na prática, segundo Athanasopoulou, Douvis e Kyriakis (2011), é que normalmente as organizações desportivas realizam ações sociais e sustentáveis a partir de duas perspectivas: pragmáticas (fazer o bem é um bom negócio) e nobre (fazer o bem é a coisa certa). A segunda perspectiva é realçada por De Woot (2017, p. 59), que prescreve às organizações desportivas um papel de maior protagonismo no progresso da sociedade, através de um envolvimento em dimensões culturais, políticas e sociais, afirmando que só é possível a consolidação dos negócios num cenário de desenvolvimento humano sustentável.

Babiak, Mills, Tainsky e Juravich (2012) referem que os gestores das organizações desportivas demonstram uma crescente preocupação com a imagem que transmitem, 
sobretudo ao nível das comunidades em que estão inseridas, e isso implica dispensar atenção às questões sociais deste público, especialmente se considerarmos o que refere Costa (1997), que considera o futebol para lá de um simples jogo, entendendo-o como um produto da sociedade, repleto de elementos identitários e simbológicos. O futebol configura-se, assim, no nosso entendimento, como uma atividade capaz de criar impacto no comportamento dos cidadãos, podendo gerar benefícios não apenas para as comunidades, mas permitindo às organizações desportivas estabelecer uma conexão com a sociedade.

\section{A COMUNICAÇÃO DA RESPONSABILIDADE SOCIAL PELAS ORGANIZAÇÕES DESPORTIVAS EM PORTUGAL E NO BRASIL}

As organizações modernas assumem novas posturas na sociedade atual. A velocidade das mudanças que ocorrem em todos os campos impele as organizações a um novo comportamento institucional perante a opinião pública. Elas passam a preocupar-se mais com as relações sociais, com os acontecimentos políticos e com os factos económicos mundiais. E, nesse contexto, a atuação de relações públicas será fundamental, pois caberá a essa atividade a função de abrir canais de diálogo com os diferentes segmentos da sociedade, administrando estrategicamente a comunicação (Kunsch, 1997, p. 141).

Segundo Henriques e Neto (2001, p. 5), os comunicadores passam a desempenhar um importante papel ao assessorarem as organizações, com o objetivo de lhes dar visibilidade e ajudar na promoção e desenvolvimento de projetos comunitários, campanhas sociais e de preservação de natureza, contribuindo dessa forma para uma reconfiguração do status das organizações na sociedade. Para atingir este nível de comprometimento, Vieira (2004), ao refletir sobre o papel da comunicação nas organizações, que gera impacto nas pessoas e na sociedade, adverte que "nessa dimensão, o comprometimento da gestão é fundamental, sobretudo na gestão da política de comunicação" (p. 24), ou seja, é preciso que a organização tenha conhecimento da capacidade de transformação da comunicação e atue nesse sentido, garantindo ao mesmo tempo que está em sintonia com a cultura organizacional (Dozier et al., 2013).

É preciso considerar o poder de influência da comunicação na projeção dos eventos junto da opinião pública, sendo capaz de evidenciar os temas sobre os quais o público precisa estar informado (McCombs \& Shaw, 1972). No entanto, importa sublinhar a significativa alteração na comunicação com os públicos. A Internet 
acelerou a circulação da informação e transformou também o acesso por parte dos cidadãos, tirando a hegemonia dos jornalistas e dos media tradicionais na difusão da informação (Fidalgo, 2008, p. 169).

É neste cenário que as organizações desportivas ganham legitimidade para contribuir para o desenvolvimento da sociedade, ou seja, considerando o seu poder em termos de comunicação. O desporto é cada vez mais visto como uma poderosa forma de comunicação, que, segundo L’Etang (2006), necessita de mais contributos teóricos para compreender este fenómeno. Muitas obras versam sobre a comunicação desportiva nos media tradicionais e não sobre as organizações desportivas. Alcoba (1987) aborda a génese social do desporto, uma força universal capaz de unir os povos numa relação amigável, acima de crenças, classes e ideologias.

É percebendo a comunicação como uma ferramenta de caráter estratégico, alinhada com os paradigmas organizacionais e atenta às transformações da sociedade, que se torna fundamental analisar também a comunicação desportiva a partir das ações pensadas para e através das novas tecnologias de comunicação digital. Gonçalves e Elias (2013) consideram a emergência da Web 2.0 como "um canal de comunicação extremamente importante na construção de relações entre as organizações e os públicos" (p. 135), uma oportunidade que as organizações desportivas têm de potenciar para comunicar com os seus adeptos, mas também com os restantes cidadãos (Skinner, 2010).

É através da comunicação que o desporto, essa instituição social relevante, como explica Godfrey (2009), pode ser um instrumento de legitimação dos sistemas políticos, económicos e, sobretudo, sociais. Neste contexto, importa realçar que ao assumir um posicionamento de responsabilidade social, a sincronia entre a comunicação e as práticas organizacionais deve ser real e verdadeira, como realça Vieira (2004), sob pena de, ao agir apenas retoricamente, não ser capaz de envolver, atingir ou influenciar o público.

\section{METODOLOGIA E DESENHO DE INVESTIGAÇÃO}

A investigação sobre as práticas comunicacionais dos clubes de futebol visando a responsabilidade social é um campo ainda pouco explorado e, portanto, muito vasto e em constante transformação. É neste sentido que optamos pela realização de um estudo de caso, uma vez que este "investiga um fenómeno no seu ambiente natural, quando as fronteiras entre o fenómeno e o contexto não são bem defini- 
das" (Yin, 1994, p. 13). Esta abordagem metodológica é também a "mais adequada quando queremos saber o "como" e o "porquê" de acontecimentos atuais sobre os quais o investigador tem pouco ou nenhum controlo" (Yin, 1994, p. 9). No caso da nossa investigação, o estudo de caso assume-me como múltiplo (Bogdan \& Biklen, 1994; Yin, 1994), na medida em que considera os clubes participantes da I Liga de Portugal na época 2021/2022 (18) e os clubes participantes da Série A, do Brasil, na época 2021 (20) (Tabela 1). De acordo com a classificação de Stake (1995) poderíamos também dizer que é um estudo de caso coletivo, uma vez que procura "pela comparação, conhecimento mais profundo sobre o fenómeno, população ou condição" (Coutinho, 2015, p. 338).

\section{Tabela 1}

Lista de clubes de cada país considerados na análise

\begin{tabular}{cc}
\hline I Liga de Portugal & Série A do Brasil \\
\hline Sport Lisboa e Benfica & Sport Club Internacional \\
Futebol Clube do Porto & Clube de Regatas do Flamengo \\
Sporting Clube de Portugal & Clube Atlético Mineiro \\
Clube Desportivo Santa Clara & São Paulo Futebol Clube \\
Vitoria Sport Clube & Santos Futebol Clube \\
Sporting Clube de Braga & Fluminense Football Club \\
Club Sport Marítimo & Fortaleza Esporte Clube \\
Gil Vicente Futebol Clube & Sociedade Esportiva Palmeiras \\
Clube Desportivo Nacional & Atlético Clube Goianense \\
Moreirense Futebol Clube & Grêmio Foot Ball Porto Alegrense \\
Belenenses SAD & Sport Club do Recife \\
Futebol Clube de Famalicão & Esporte Clube Bahia \\
Futebol Clube Paços Ferreira & Ceará Sporting Club \\
Portimonense Sporting Clube & Botafogo de Futebol e Regatas \\
Rio Ave Futebol Clube & Club de Regatas Vasco da Gama \\
Clube Desportivo de Tondela & Sport Club Corinthians Paulista \\
Boavista Futebol Clube & Club Athletico Paranaense \\
Sporting Clube Farense & Coritiba Foot Ball Club \\
& Red Bull Bragantino \\
& Goiás Esporte Clube \\
\end{tabular}

Fonte: Elaboração dos autores. 
Importa realçar que a investigação se assume também como um estudo de um caso particular, na medida em que se considera a comunicação realizada por parte dos clubes numa plataforma específica, a rede social digital Facebook, escolhida tendo em conta que é a mais utilizada, em Portugal e no Brasil. Foi nesse ambiente digital que procedemos à observação e análise das contas oficiais dos clubes de futebol da I Liga, em Portugal, e da Série A, do Brasil, com o objetivo de verificar o posicionamento e a veiculação de campanhas de responsabilidade social no Dia Internacional da Mulher, 8 de março de 2021.

Embora os estudos de caso sejam, pelo seu forte carácter descritivo, muitas vezes associados às investigações qualitativas, esta estratégia de investigação também pode ser adotada no âmbito de investigações quantitativas ou mistas (Coutinho, 2015, pp. 336-337). Por outro lado, no processo de recolha de dados, os estudos de casos podem recorrer a diferentes técnicas ou "múltiplas fontes de evidência" (Yin, 1994, p. 13), que podem permitir o cruzamento da informação e o aprofundamento dos dados recolhidos (Coutinho, 2015). Nesta investigação optámos por recorrer à análise de conteúdo, considerando que enquanto "conjunto de técnicas que permitem analisar de forma sistemática um corpo de material textual, por forma a desvendar e quantificar a ocorrência de palavras/frases/temas considerados "chave" que possibilitem uma comparação posterior" (Coutinho, 2015, p. 217), seria o método que melhor nos permitiria alcançar os objetivos propostos. Interessa ainda frisar que o tipo de análise de conteúdo conduzido não considerou categorias pré-definidas, e foi por isso de cariz exploratório, uma vez que “...os resultados são devidos unicamente à metodologia de análise, estando isenta de qualquer referência a um quadro teórico preestabelecido" (Ghiglione \& Matalon, 1997, p. 210). Assim, e de acordo com essa abordagem exploratória, procuramos identificar o número de publicações realizadas por parte dos clubes; o impacto que as publicações tiveram, aqui medido em termos de número de gostos, comentários e partilhas; e ainda a a forma como essas publicações têm relação com o quinto Objetivo do Desenvolvimento Sustentável, que defende a Igualdade de Género.

Na próxima secção apresentamos os principais resultados que obtivemos com a recolha feita nas páginas dos clubes na rede social digital Facebook. A apresentação dos resultados terá em conta uma análise essencialmente quantitativa, considerando os procedimentos metodológicos apresentados, mas procurará também, na lógica de um estudo comparativo, identificar tendências em cada um dos países. Neste contexto, tratando-se de um trabalho exploratório, que procura sobretudo identificar 
a presença de uma comunicação orientada para um determinado objetivo por parte dos clubes, não se procede a uma análise crítica dos discursos ou das mensagens, assinalando-se apenas a sua presença como forma de sinalizar a importância de um dia que alerta para o papel e os direitos das mulheres na sociedade.

\section{APRESENTAÇÃO E DISCUSSÃO DOS RESULTADOS PRELIMINARES}

Começamos a apresentação dos resultados, destacando o número de publicações que identificámos em cada um dos países. No caso português, dos 18 clubes que participaram na I Liga de Portugal na época 2021/2022, verificámos que todos fizeram pelo menos uma publicação para assinalar o Dia Internacional da Mulher. No total identificámos 33 publicações relacionadas com o Dia da Mulher, apesar de, como veremos mais à frente, nem todos os posts terem o mesmo tipo de enquadramento. Já no caso da Série A do Brasil, verificámos também que todos os 20 clubes fizeram pelo menos uma publicação para assinalar o dia. No total foram identificadas 45 publicações, que tiveram também objetivos distintos, destacando-se ainda o facto de alguns clubes apostarem numa comunicação mais personalizada, desenvolvida não apenas para assinalar o dia, mas para tratar vários dos objetivos consagrados no Objetivo do Desenvolvimento Sustentável.

Observando em particular a distribuição das publicações, podemos verificar que no caso português, para além de a distribuição ser desigual entre os clubes, dos 33 posts identificados, apenas 10 se encontram alinhados com o $5^{\circ}$ Objetivo do Desenvolvimento Sustentável que guiou este trabalho, mas também com os seus objetivos específicos. 


\section{Figura 1}

\section{Distribuição das Publicações Analisadas por Clube e Tipologia}

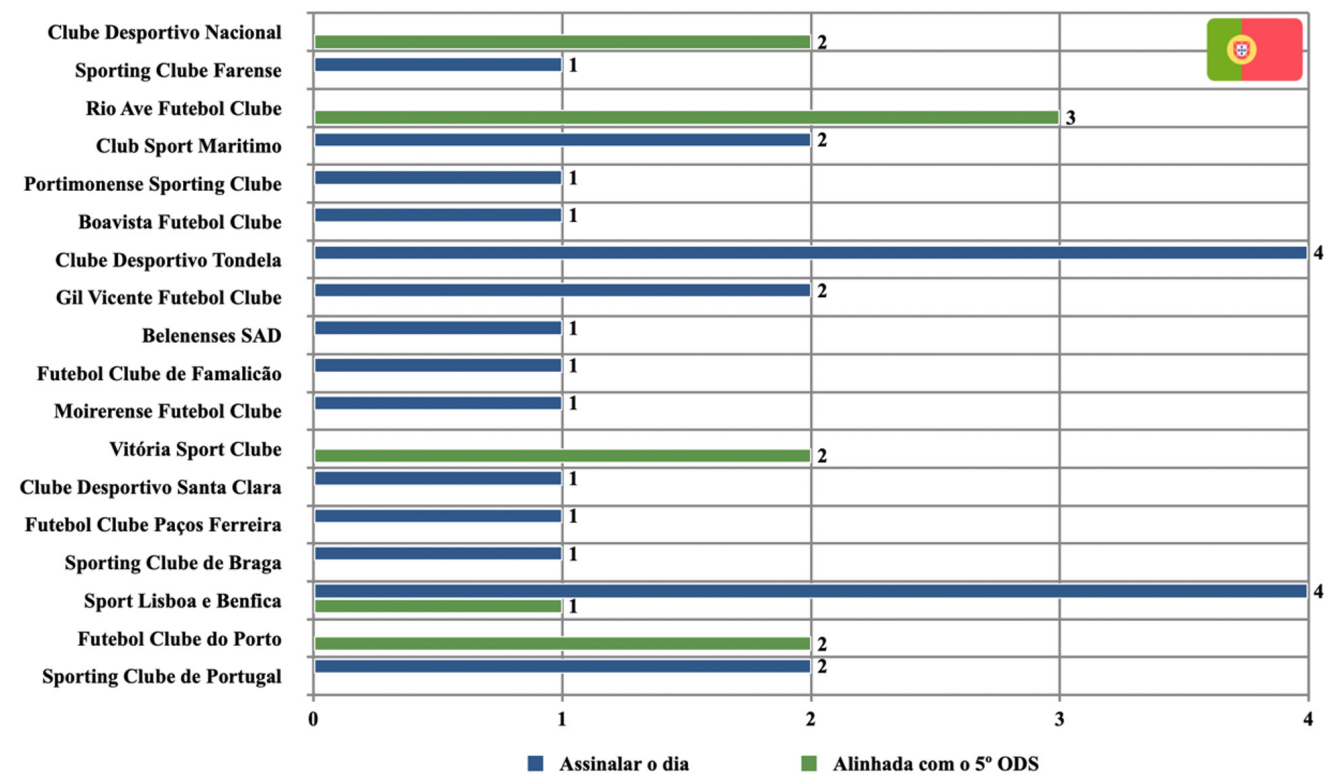

Fonte: Elaboração dos autores

A título de exemplo podemos referir as campanhas do Vitória Sport Clube ${ }^{1}$ ou do Rio Ave Futebol Clube², que através de vídeos procuraram transmitir mensagens contra o assédio de que as mulheres e raparigas são vítimas, mas alertam também para a necessidade de combater as construções de feminilidade e masculinidade, ainda muito presentes na sociedade e que continuam a associar a prática desportiva, em muitas situações, à dimensão física e à resistência. Os dados recolhidos ajudam-nos também a perceber que embora todos os clubes tenham assinalado o dia, apenas alguns desenvolveram campanhas que procuram efetivamente promover um conjunto de valores que se encontram alinhados com o objetivo de alcançar a igualdade de género e empoderar todas as mulheres e raparigas. Desta forma, fica claro que nem todos os clubes conferem a mesma importância ao tema ou que nem todos detém capacidade de desenvolver campanhas capazes de passar uma mensagem que possa

1 Link da publicação [url] https://www.facebook.com/vitoriasportclube/posts/10158453935288167

2 Link da publicação [url] https://www.facebook.com/rioavefc/posts/3683621808372481 
contribuir, de alguma forma, para iniciar uma mudança na sociedade. Considerando que alguns dos exemplos identificados não foram desenvolvidos pelos clubes com maior poder económico e/ou com estruturas organizativas mais sólidas, não podemos argumentar que se trata de uma falta de recursos, mas antes de uma ausência de estratégia de responsabilidade social. Esta questão é sobretudo evidente se considerarmos que estes dias internacionais servem não apenas para assinalar as datas, mas para lembrar que existe ainda um longo caminho a percorrer, e neste caso em específico, para acabar com as disparidades entre géneros. A ausência de um posicionamento mais vincado, e de uma mensagem que considere a realidade das mulheres no desporto, pode ser entendido como falta de acompanhamento do que se passa na sociedade ou percepção de que não existem desigualdades.

Cabe salientar que nas campanhas lançadas por alguns dos clubes, se adota uma comunicação orientada para as gerações mais novas, nomeadamente alertando para o papel que as redes sociais digitais adquiriram na divulgação de imagens e vídeos de mulheres sem o seu consentimento, mas também no fomento dos discursos discriminatórios e de ódio. Esta estratégia dos clubes revela uma atenção particular para alguns dos problemas que marcam as nossas sociedades e que afetam as mulheres, numa abordagem em que o futebol e os atletas não são elementos centrais das campanhas, mas espaços e atores capazes de chamar a atenção para os problemas através da sua notoriedade e visibilidade pública.

Já no caso brasileiro, se o número de publicações não é muito superior àquele que identificámos nas páginas dos clubes portugueses, já ao nível do seu enquadramento, registamos diferenças significativas, uma vez que das 45 publicações analisadas, 33 estão em linha com as ideias defendidas no ODS considerado. Quer isto dizer que no contexto brasileiro, quase $75 \%$ dos posts feito pelos clubes na rede social Facebook, não se limitaram a assinalar o Dia Internacional da Mulher, mas procuraram passar uma mensagem relacionada com a importância de combater as desigualdades e ajudar na afirmação do papel da mulher. Neste contexto destaca-se por exemplo o vídeo partilhado pela Sport Club Internacional, que realçou o papel das mulheres no combate à pandemia de COVID-193. Este exemplo, como outros que identificámos na análise, remetem para a importância de as estruturas comunicacionais dos clubes estarem atentas à atualidade e aproveitarem os seus canais para dar conta de que existe um acompanhamento do que se passa fora das quatro linhas e do que impacto que esses acontecimentos podem ter na sociedade.

3 Link da publicação [url] https://www.facebook.com/scinternacional/posts/3941631659209389 


\section{Figura 2}

Distribuição das Publicações Analisadas por Clube e Tipologia

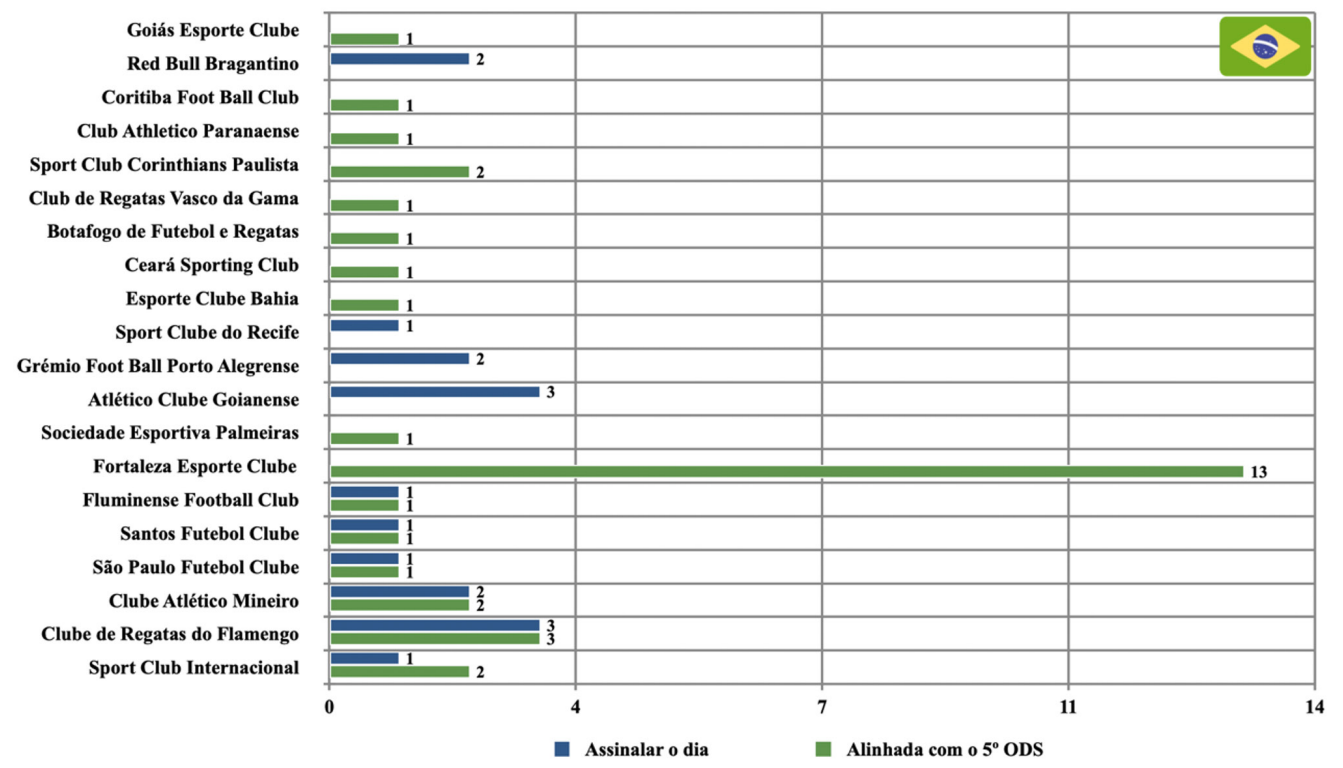

Fonte: Elaboração dos autores

Os dados permitem-nos, numa abordagem comparativa, perceber que existem diferenças entre os dois países, mas observar também que no caso brasileiro há vários clubes que apostaram apenas em conteúdos que estão alinhados com o Objetivo de Desenvolvimento Sustentável. Por outro lado, é também interessante verificar, nos dois países, que não são os clubes de maior dimensão ou com maior poder económico que mais apostam nestas campanhas. Percebe-se assim que os clubes que apostam nestas campanhas, que enquadram numa lógica de Responsabilidade Social Corporativa procuram mais do que uma vantagem económica, a construção de uma imagem positiva sobre o clube, através da tomada de posição e da expressão de um conjunto de atitudes.

Por fim, merece nota o facto de os clubes brasileiros estarem mais atentos a esta questão, como provavelmente a outras questões apresentadas nos ODS, o que necessariamente deve ser considerando tendo em conta as próprias desigualdades que se verificam numa sociedade de maior dimensão e com problemas mais acentuados, resultado também da situação política em que se encontra. No caso particular da 
questão que abordamos neste trabalho, importa lembrar que de acordo com os dados do Instituto Brasileiro de Geografia e Estatística (IBGE), apresentados na segunda edição do estudo "Estatísticas de gênero: indicadores sociais das mulheres no Brasil" (2021), os diferentes indicadores analisados continuam a revelar desigualdades expressivas entre homens e mulheres. Verifica-se, por exemplo, que "a responsabilidade quase duas vezes maior por afazeres domésticos e cuidados ainda é fator limitador importante para uma maior e melhor participação no mercado de trabalho, pois tende a reduzir a ocupação das mulheres ou a direcioná-las para ocupações menos remuneradas" (IBGE, 2021, p. 12). Por outro lado, verifica-se também que "a associação do gênero feminino ao trabalho não-remunerado no âmbito doméstico parece influenciar, inclusive, as trajetórias e escolhas de uma formação superior: a maior parte das mulheres se formam em cursos relacionados a cuidados e bem-estar (professoras, assistentes sociais, enfermeiras, entre outras)" (IBGE, 2021, p. 12). Estas duas questões, bem como os dados que dão conta que cerca de cem crianças e adolescentes de até 14 anos são violadas por dia no Brasil, sendo que dessas $86 \%$ são meninas, de acordo com os dados recolhidos pelo Fórum Brasileiro de Segurança Pública em parceria com a Unicef, podem ajudar a explicar a atenção que os clubes conferem a este dia, e sobretudo as campanhas que tentam desenvolver. A comunicação dos clubes é assim orientada para a colocação destes assuntos na agenda pública, tentando dessa forma que sejam formuladas "políticas públicas de suporte às agendas de promoção de equidade, de acesso a oportunidades e de proteção contra violência doméstica, assédio e abusos de toda ordem" (IBGE, 2021, p. 12).

Olhando para os dados recolhidos podemos também verificar, no que diz respeito ao impacto das publicações, que no caso português as 33 publicações geraram 51,291 gostos, tendo sido partilhadas 5411 vezes. Já em termos de comentários, os posts foram comentados 2170 vezes. Apesar de nem sempre serem os clubes de maior dimensão os que mais publicações fizeram, a verdade é que, no contexto português, se nota que a sua influência e número de seguidores acaba por ter maior repercussão nas redes sociais digitais.

Vale também referir que as publicações que se encontram alinhadas com o $5^{\circ}$ Objetivo de Desenvolvimento Sustentável que nos guiou, então entre as que geraram mais "likes", ou seja, 56\% dos "gostos" dizem respeito a essas publicações que não assinalam apenas o dia, mas procuram transmitir uma mensagem alinhada com a necessidade de mudança. Verificamos também que 49\% dos comentários são feitos nestas publicações, tal como $42 \%$ das partilhas. Merece ainda nota o facto de todas as 
publicações recorrerem a texto, quase metade (12) não utilizar fotografias nas publicações e a outra metade (12) recorrer ao vídeo, sendo que esse recurso é utilizado em apenas três posts alinhados com o ODS. A dimensão audiovisual não é assim privilegiada para transmitir as mensagens, mas pelo contrário a aposta é quase sempre no texto e na fotografia.

\section{Figura 3}

Distribuição do Número de Gostos, Comentários e Partilhas por País e Tipo de Publicações

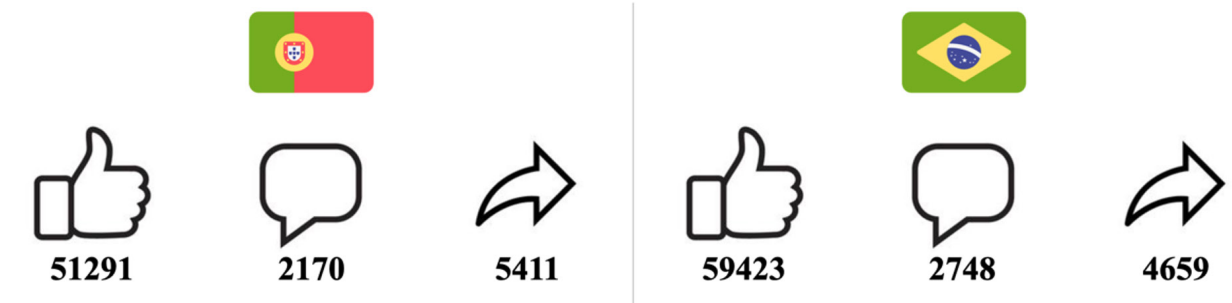

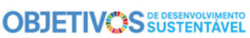

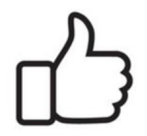

28933

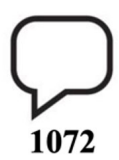

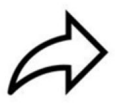

2273

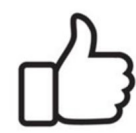

45099
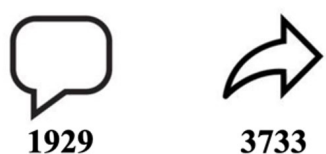

3733

Já as publicações dos clubes brasileiros apresentam 59,423 gostos, tendo um total de 2748 comentários e sendo partilhadas 4659 vezes. Ao contrário do que acontece em Portugal, as reações não estão concentradas nos clubes de maior dimensão, mas pelo contrário assiste-se a uma distribuição dos gostos, comentários e partilhas por todos os clubes e em função dos conteúdos e mensagens dos posts.

Podemos ainda verificar que, sendo verdade que o número de publicações alinhadas com o $5^{\circ}$ ODS é maior que no caso dos clubes portugueses, é também muito superior a percentagem dessas publicações que acabam por obter reações. Quer isto dizer que do total de posts dos clubes brasileiros, $76 \%$ dos gostos dizem respeito a posts que estão alinhados com o Objetivo de Desenvolvimento Sustentável, da mesma forma que foram esses que tiveram $70 \%$ dos comentários e $80 \%$ das partilhas. Percebemos desta forma que estas publicações, que têm uma mensagem claramente orientada para a igualdade de género e o empoderamento das mulheres, obtêm mais reações. Estes dados sugerem 
também que os clubes brasileiros usam com maior frequência os canais digitais para comunicar com os seus públicos, não apenas sobre as questões do jogo propriamente dito, mas sobre os mais variados assuntos e, em particular, questões de interesse público e com impacto na sociedade. A maior reação por parte dos seguidores, por outro lado, remete para uma possibilidade de intervenção mais efetiva, ou seja, uma possibilidade não apenas de passar uma mensagem, mas de levar à ação.

Em relação ao conteúdo das publicações, é importante referir que tal como em Portugal, todos os posts têm texto, quase metade (18) foto e mais de metade (28) vídeo, sendo que entre os posts que estão alinhados com o ODS, o vídeo é quase sempre privilegiado (acontece em 22 das 33 publicações). A aposta na dimensão audiovisual é evidente por parte dos clubes brasileiros, que procuram dessa forma passar uma mensagem mais imediata, ao mesmo tempo que alinham as suas campanhas com as tendências ao nível de consumo de conteúdos online.

Por fim, no que diz respeito às temáticas e mensagens das publicações que estão alinhadas, de forma clara, com o $5^{\circ}$ Objetivo de Desenvolvimento Sustentável, destacam-se, no caso português, os posts que promovem a luta contra o preconceito e discriminação contra as mulheres, os que procuram combater o abuso psicológico e sexual, mas também os que destacam o papel de superação das mulheres e a necessidade de estas alcançarem mais cargos de gestão. Interessa lembrar que Portugal, e de acordo com os dados do Instituto Europeu para a Igualdade de Género (EIGE), ocupa a décima sexta posição na UE no Índice de Igualdade de Género, com uma pontuação que se encontra 6,6 pontos abaixo da média da EU (EIGE, 2020).

Já no caso brasileiro, a maioria das publicações promove a igualdade e respeito pelas mulheres, destacando-se aquelas que focam a violência doméstica, a necessidade de ter mais mulheres nos lugares de decisão, sem esquecer o papel da mulher no combate à pandemia, dentro e fora dos hospitais. Este último ponto é particularmente importante, na medida em que a pandemia afetou homens e mulheres, mas fez-se sentir de forma mais significativa na esfera feminina, uma vez que a sobreposição de responsabilidades ao nível do trabalho e no espaço doméstico, se intensificou durante a pandemia, realçando, uma vez mais a falta de participação por parte dos homens e a desproporcionalidade de atividades que recaem sobre as mulheres (WEF, 2021). Por outro lado, verificamos que nas campanhas dos clubes se procura destacar o papel que as mulheres tiveram no campo da saúde, alertando precisamente para o duplo papel que tiveram de assumir durante a pandemia e que contribuiu para um acentuar das desigualdades. 


\section{CONSIDERAÇÕES FINAIS}

Iniciámos este estudo com o objetivo de perceber a importância que os clubes de futebol da I Liga de Portugal e da Série A do Brasil conferem, enquanto organizações desportivas, à comunicação de responsabilidade social, nomeadamente à figura da mulher na sociedade. Partindo das publicações feitas para assinalar o Dia Internacional da Mulher, verificámos que o futebol se pode jogar muito para lá das quatro linhas, tendo um papel importante na transmissão de mensagens que estão alinhadas com os Objetivos do Desenvolvimento Sustentável, e neste caso em concreto, com a promoção da igualdade de género e do empoderamento feminino. A maioria das publicações identificadas e analisadas não se limitam a assinalar o dia, mas procuram transmitir uma mensagem, conferindo assim ao futebol um papel não apenas no campo do entretenimento, mas sobretudo no da transformação social. Os dados apresentados são ainda preliminares e precisam de ser explorados, nomeadamente com uma análise mais aprofundada das publicações, mas também das reações, para se perceber o impacto que podem ter numa sociedade ainda muito desigual. No entanto, podemos já concluir que as principais questões que continuam a marcar o debate sobre as disparidades entre géneros são transpostas para o futebol através das campanhas desenvolvidas pelos clubes. Não cabendo neste trabalho uma análise mais aprofundada das opções tomadas por cada uma das organizações desportivas, é válido destacar que as publicações alertam para o facto de o desporto, e particularmente o futebol, ser ainda considerado um domínio de homens, em grande medida devido às construções sociais de masculinidade. A ideia de que existem características, como a força física, que são exclusivas dos homens e que as praticantes femininas acabam por ser vistas como "masculinas", estão entre os estereótipos que prevalecem na sociedade e que os clubes procuram de alguma forma desconstruir. Por outro lado, são várias as campanhas que alertam para as questões da violência baseadas no género, mas também para o papel que as tecnologias passaram a ter ao nível da disseminação de conteúdos sobre as mulheres e na promoção do discurso de ódio. Existem ainda várias campanhas que destacam o papel das mulheres no combate à pandemia, numa estratégia de comunicação que destaca as desigualdades em termos de distribuição de tarefas e participação no mercado de trabalho, e que se intensificou durante os confinamentos.

Não existindo diferenças significativas entre os dois países, importa ainda assim destacar que os clubes brasileiros apostaram mais na transmissão de mensagens que 
procuram combater as desigualdades e afirmar o papel da mulher, o que pode ser entendido como um reflexo das desigualdades mais profundas que existem na sociedade. Mas pode também ser sinal de que as estruturas de comunicação dos clubes estão mais atentas a estas questões e acreditam na importância de se usar o futebol como ferramenta para comunicar questões de responsabilidade social. O impacto das campanhas, medido pelos gostos, comentários e partilhas, parece reforçar esta ideia, não apenas de maior preocupação por parte dos clubes, mas também de maior adesão por parte dos indivíduos, que estando conscientes da necessidade de promover a igualdade, veem no futebol um espaço privilegiado para que se questionem os estereótipos e se combatam as disparidades de género.

É por este motivo que consideramos que esta é uma temática que deve continuar a ser estudada, não apenas pela importância e responsabilidade que todos temos no combate às desigualdades sociais, mas sobretudo porque devemos encontrar os melhores caminhos e estratégias para alcançar os públicos, podendo o futebol ser, neste caso, um campo privilegiado para alcançar o melhor resultado no final do jogo. Enquanto estudo exploratório, este trabalho não consegue dar resposta a todas as questões, e deve por isso ser entendido como um primeiro esforço de investigação que procura chamar a atenção de se considerar o desporto, e em particular o futebol, para lá do jogo propriamente dito, mas como atividade com responsabilidade na vida em sociedade e, por isso, com obrigações ao nível da igualdade entre homens e mulheres e no combate aos estereótipos, preconceitos e concepções socialmente construídas ao longo do tempo.

\section{REFERENCIAS}

Alcoba, A. (1987). Deporte y comunicación. Universidad Complutense de Madrid. Anderson, E. (2009). The maintenance of masculinity among the stakeholders of sport. Sport Management Review, 12(1), 3-14.

Athanasopoulou, P., Douvis, J., \& Kyriakis, V. (2011). Corporate social responsibility (CSR) in sports: antecedents and consequences. Paper presented at the 4th Annual EuroMed Conference of the EuroMed Academy of Business. 
Babiak, K., Mills, B., Tainsky, S., \& Juravich, M. (2012). An investigation into professional athlete philanthropy: Why charity is part of the game. Journal of sport management, 26(2), 159-176.

Babiak, K., \& Trendafilova, S. (2011). CSR and environmental responsibility: motives and pressures to adopt green management practices. Corporate social responsibility environmental management, 18(1), 11-24.

Bauman, Z. (2001). Modernidade Líquida. Editoria Schwarcz-Companhia das Letras.

Bauman, Z. (2009). A arte da vida: Editora Schwarcz-Companhia das Letras.

Bogdan, R. \& Biklen, S. (1994). Investigação qualitativa em Educação: uma introdução à teoria e aos métodos. Porto: Porto Editora.

Bourdieu, P. (1983). Como é possível ser esportivo. Questões de Sociologia, 136-153.

Bourdieu, P. (2001). Masculine Domination. Stanford University Press.

Bowen, H. R. (1953). Social responsibilities of the businessman: University of Iowa Press.

Cardoso, G., Xavier, D., \& Cardoso, T. (2007). Futebol, identidade e media na sociedade em rede. Observatorio, 1(1), 119-143.

Castells, M. (2003). A Galáxia Internet: reflexões sobre a Internet, negócios e a sociedade: Zahar.

Constantino, J. M. (2006). Desporto: geometria de equívocos. Livros Horizonte.

Costa, A. (1997). À volta do estádio. O desporto, o Homem e a sociedade. Porto: Campos das Letras.

Coutinho, C. P. (2015). Metodologia de Investigação em Ciências Sociais e Humanas: Teoria e Prática (2a edição). Coimbra: Edições Almedina.

De Woot, P. (2017). Responsible Innovation. Routledge.

Dozier, D. M., Grunig, L. A., \& Grunig, J. E. (2013). Manager's guide to excellence in public relations and communication management. Routledge.

EIGE - Instituto Europeu para a Igualdade de Género.(2020). Índice de Igualdade de Género. Vilnius: Instituto Europeu para a Igualdade de Género.

Fidalgo, J. (2008). O jornalista em construção. Porto Editora. 
Freeman, R. E., \& McVea, J. (2001). A stakeholder approach to strategic management. In Michael A. Hitt, R. Edward Freeman, Jeffrey S. Harrison (Eds.), The Blackwell hadbook of strategic management, (pp. 189-207). Blackwell.

Frost, M., \& Sullivan, K. (2017). The sustainable development goals (SDGs). In The value for Europe. Whitepaper.

Garriga, E., \& Melé, D. (2004). Corporate social responsibility theories: Mapping the territory. Journal of business ethics, 53(1), 51-71.

Ghiglione, R., \& Matalon, B. (1997). O inquérito: Teoria e prática (3a ed.). Oeiras: Celta Editora.

Godfrey, P. C. (2009). Corporate social responsibility in sport: An overview and key issues. Journal of sport management, 23(6), 698-716.

Gonçalves, G., \& Elias, H. (2013). Comunicação estratégica. Um jogo de relações e aplicações. Comunicação digital, 133.

Guilianotti, R. (1994). Social identity and public order: political and academic discourses on football violence. In R. Giulianotti, N. Bonney, \& M. Hepworth, Football, violence and social identity, (pp. 9-36). Routledge.

Henriques, M. S., \& Neto, J. A. d. P. S. (2001). Comunicação e movimentos de mobilização social: estratégias de atuação das organizações do terceiro setor na área da comunicação. Paper presented at the Anais do XXIV Congresso Brasileiro da Comunicação. Campo Grande/MS.

Hulme, D. (2007). The making of the millennium development goals: human development meets results-based management in an imperfect world. Brooks World Poverty Institute Working Paper(16).

IBGE - Instituto Brasileiro de Geografia e Estatística (2020). Estatísticas de gênero: indicadores sociais das mulheres no Brasil (2 ed.). Instituto Brasileiro de Geografia e Estatística. Disponível em: https://www.ibge.gov.br/ estatisticas/ multidominio/ genero/20163-estatisticas-de- genero-indicadores-sociais-dasmulheres-no-brasil.html. Consultado a 28 de novembro de 2021.

Kolyperas, D. (2012). Corporate and social responsibility in professional football club organizations. University of Stirling. 
Kunsch, M. M. K. (1997). Relações públicas e modernidade: novos paradigmas na comunicação organizacional (Vol. 56). Summus Editorial.

L'Etang, J. (2006). Public relations and sport in promotional culture. Public Relations Review, 32(4), 386-394.

Marques dos Santos, P. M., Antunes, S., \& Guedes, A. (2019). Os objetivos do milénio - os resultados de 2015 e prospetiva para 2030. In Anais do I Congresso Global de Direitos Humanos. Novas políticas de cidadania e de desenvolvimento sustentável. (1 ${ }^{\text {a }}$ ed., pp. 355-367). Editora da Universidade de São Luís do Maranhão.

McCombs, M. E., \& Shaw, D. L. (1972). The agenda-setting function of mass media. Publi opinion quarterly, 36(2), 176-187.

Mibielli, P., \& Barcellos, F. C. (2014). Os Objetivos de Desenvolvimento do Milênio (ODMs)-: uma avaliação crítica. Histórias, histórias, 5(3), 222-244.

Okado, G. H. C., \& Quinelli, L. (2016). Megatendências Mundiais 2030 e os Objetivos de Desenvolvimento Sustentável (ODS): uma reflexão preliminar sobre a" Nova Agenda" das Nações Unidas. Revista Baru-Revista Brasileira de Assuntos Regionais e Urbanos, 2(2), 111-129.

Panton, M. (2012). Football and corporate social responsibility. Birkbeck Sport Business Centre Research Paper Serie, 5(2), 1-84.

Pedersen, P. (2017). Routledge handbook of sport communication. Routledge.

Skinner, J. (2010). Sport social responsibility. Sport public relations and communication, 69-86.

Stake, R. E. (1995). The art of case study research. Thousand Oaks, CA: Sage Publications.

Tichy, N. M., McGill, A. R., \& Clair, L. S. (1997). Corporate global citizenship: Doing business in the public eye. Lexington Books.

Vieira, R. F. (2004). Comunicação Organizacional. Mauad Editora Ltda.

Votaw, D. (1973). Genius becomes rare: a comment on the doctrine of social responsibility Pt. II. California management review, 15, 19-5. 
Walters, G., \& Tacon, R. (2011). Corporate social responsibility in European football. Birkbeck Sport Centre Research Paper, Vol. 4, 1-101.

Wisnik, J. (2008). Veneno remédio: o futebol e o Brasil. São Paulo: Companhia das Letras.

World Economic Forum (WEF) (2021). Global Gender Gap Report 2021. Geneva: Worl Economic Forum. Disponível em: http://reports.weforum.org/globalgender-gap-report-2021/dataexplorer. Consultado a 28 de novembro de 2021.

Yin, R. K. (1994). Case study research: design and methods (2a ed). Thousand Oaks, CA: Sage Publications. 